\title{
LA REPRESENTACIÓN DEL ESPACIO-TIEMPO EN EL DISEÑO GRÁFICO
}

\author{
Eréndida Cristina Mancilla González \& \\ Manuel Guerrero Salinas
}

\section{Resumen}

Tomando como base que las imágenes son, siempre, modelos de realidad, independientemente del nivel de realidad que posean, este escrito se enfoca en el establecimiento de la relación entre la realidad espacio-temporal y su representación en la imagen; de ahí que es importante ahondar en esta última, para poder dar sentido a la aprehensión del espacio y del tiempo real en su representación visual, mediante nexos que permitan establecer una dialéctica entre ambos aspectos, el material y el mental. El mundo real posee un sinnúmero de características físicas que son un referente a considerar para llevar al plano de la representación bidimensional del diseño gráfico. Es así como se da la relación entre lo real y lo virtual, entre lo material y lo mental, en donde el diseño opera, bajo el límite que le impone su propia naturaleza bidimensional.

Palabras clave: Espacio-tiempo, representación, metáfora, analogía, complejidad.

Keywords: Space - time, representation, metaphor, analogy, complexity. 
lespacio y el tiempo, dentro del diseño gráfico, son dos conceptos virtuales,
no en oposición a lo real, sino en función de que aquello a lo que se refieren
es una representación o un modo de escritura a través de elementos configurantes que contribuyen a materializar, en la composición, esos rasgos espacio-temporales, mediante una relación de semejanza 0 analogía con lo existente en la realidad, con lo real, mediante la producción de efectos similares a los que produce la realidad. Esto mediante la existencia de conocimientos y representaciones previas, que permitan comprender lo percibido mediante relaciones isomórficas, aunado a ello es importante contemplar que toda percepción implica necesariamente una interpretación.

El diseño gráfico, como disciplina, actúa mediante signos y símbolos que nos remiten a otra cosa, a la que representan o con la que están en relación, ya sea por parecido o por evocación. La experiencia es la que nos permite considerar algo como cosa y/o como signo; lo que de alguna manera nos indica que, en muchas ocasiones al menos, ser signo es una función que adquieren las cosas. Por lo demás, hay signos que tienen un gran parecido con las cosas que representan, y eso nos puede llevar a confundirlas con las cosas mismas (Castañares, 2007).

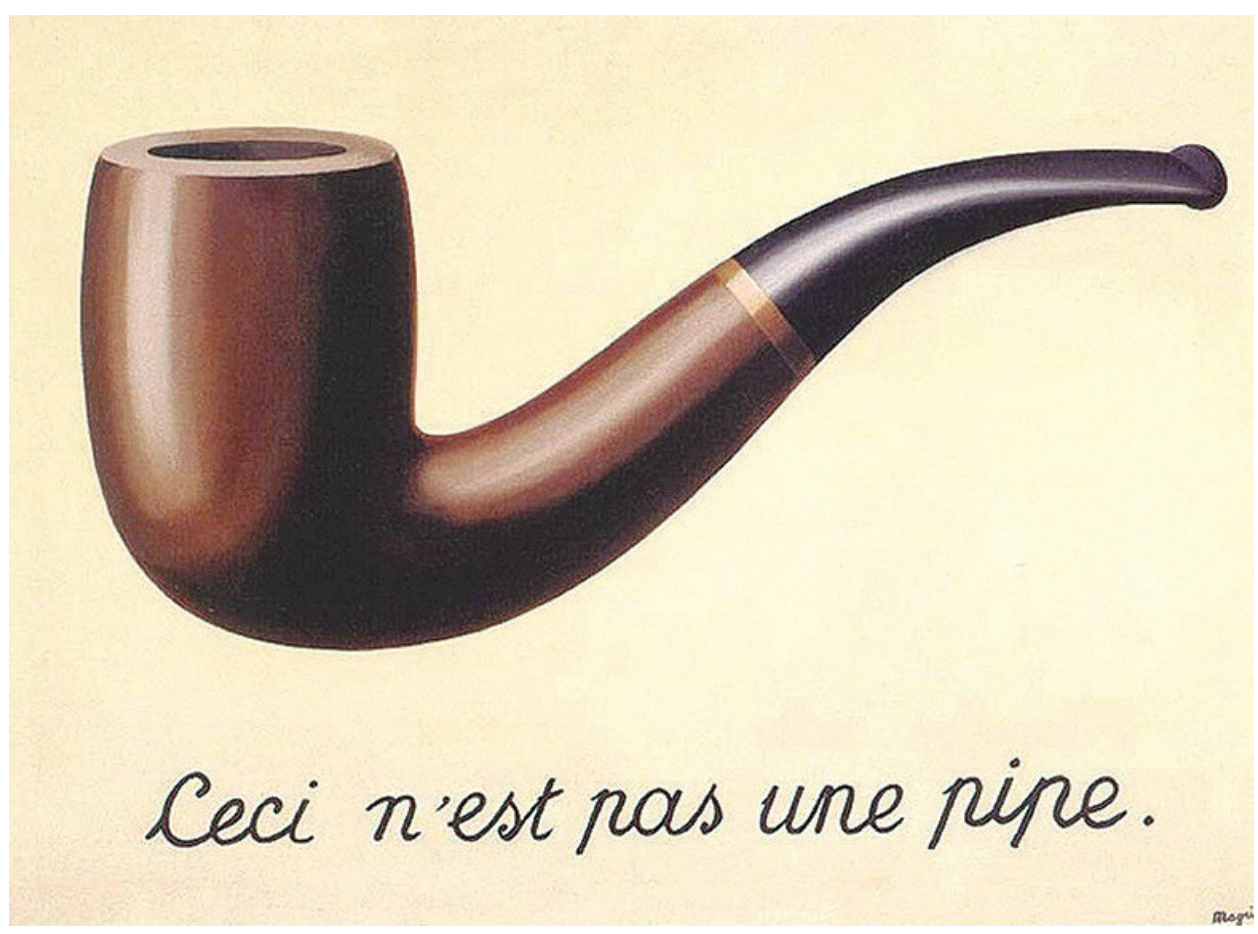

Figura 1. La Trahison des images. Bajo el dibujo nítido y realista de una pipa de fumar escribió: Esto no es una pipa, despojando de convenciones semánticas a una representación que no es el objeto, pero que de manera trivial todo el mundo acaba aceptando que lo es (Magritte, 1929). 


\section{Analogías y metáforas para la representación del espacio-tiempo}

El vínculo del espacio-tiempo representado con lo real se establece a través de dos mecanismos básicos, mediante las relaciones de similaridad (dadas por analogía u homologación) y las metafóricas (dadas por significación). Ambos mecanismos presentan complementariedad; por un lado, la analogía establece una relación comparativa con la realidad; y por el otro, el proceso metafórico establece la relación de similitud a través de la organización interna de los sememas (Beristáin, 2003). Mientras que la primera es manifiesta, la segunda es implícita; la analogía aparece como algo exterior, la metáfora, como algo interno, que no puede sustituirse ni omitirse (Ferrater, 2004).

La analogía es entendida como conjunto o sistema de relaciones lógicas, que promueve por semejanza el carácter transitivo de esas relaciones; establece que los objetos tienen la capacidad de relacionarse, abriendo la posibilidad de ampliar esas relaciones. La analogía puede ser entendida como la correspondencia estructural, al tipo de relación que se da entre las partes de dos sistemas semióticos de diferente naturaleza; correlación fundada en las conexiones que establecen entre sí ambos sistemas distintos (Beristáin, 2003). Estas relaciones se descubren mediante una operación de análisis semántico que consiste en formular un razonamiento analógico, para poder establecer una relación de semejanza entre cosas, que en esencia, son distintas, como el espacio y el tiempo real con el espacio y el tiempo representacional. De ella se desprenden conceptos como: semejante, igual e idéntico. Donde lo idéntico se entiende como lo uno en sustancia; lo igual, como lo uno en cantidad y finalmente lo semejante, como lo uno en cualidad (Ib.), de esta manera se da una relación de homologación entre la realidad y la representación.

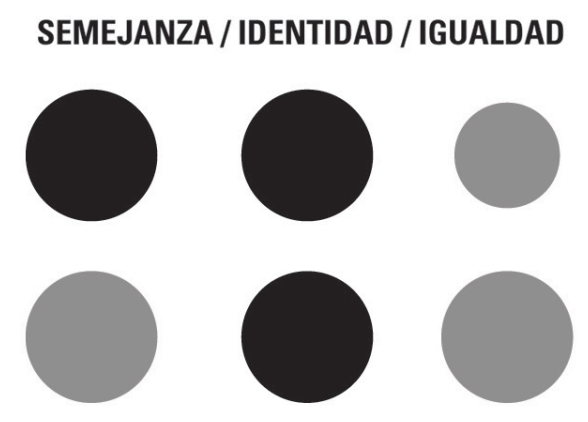

Semejante: Lo uno en cualidad Idéntico: Lo uno en sustancia Igual: Lo uno en cantidad

Figura 2. En el esquema se muestra la relación entre lo semejante, lo igual y lo idéntico en la analogía (Mancilla, 2011). 
La metáfora es un instrumento cognoscitivo de naturaleza asociativa, nacido de la necesidad y de la capacidad humana de raciocinio, es el modo fundamental que se establece para la correlación de nuestra experiencia y nuestro saber, produce un cambio de sentido o un sentido figurado opuesto al sentido literal o recto, que ofrece una connotación discursiva diferente de la denotación que los términos implicados poseen (Beristáin, 2003). La metáfora tiene el papel de introducir lo nuevo a partir de lo ya conocido. Detrás de cada concepto hay implícita una metáfora, cualquier cosa puede ser concebida en términos de otra, esto es como si..., lo cual permite construir una explicación y ordenar el sentido frente a algo que resulta nuevo.

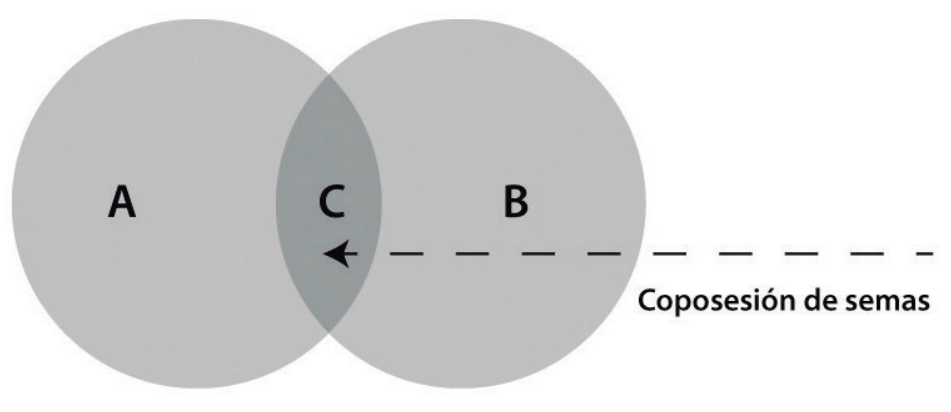

Figura 3. El gráfico ejemplifica las relaciones entre dos elementos que comparten una semejanza parcial, mediante semas comunes, gracias a los cuales se da la construcción de la metáfora (Mancilla, 2013).

Esta capacidad resulta conveniente para explicar la cuestión espacio-temporal y tempo-espacial en el diseño gráfico, dado que otorga los elementos necesarios para poder representar en el plano bidimensional estos conceptos presentes en el mundo real. En la representación del espacio-tiempo para el diseño, el papel de la metáfora consiste en introducir lo nuevo a partir de lo ya conocido, en donde un espacio representado no es un espacio real, es como un espacio real; el tiempo representado no es el tiempo real, es como el tiempo real.

No hay que olvidar que la metáfora posee un carácter fundamentalmente cognitivo y contribuye a la construcción de conceptos (en sentido figurado) que determinan nuestra comprensión del mundo. Las metáforas, entendidas en sentido aristotélico como la transferencia del nombre de un objeto a otro, son necesarias para la comprensión de las cosas que nos rodean y que de manera literal no podemos explicar.

En la mayoría de los casos, las imágenes significan algo exterior y tienen la finalidad de hacer que ese algo se vuelva imaginable para nosotros abstraerlo, reduciendo sus cuatro dimensiones de espacio y 
tiempo a las dos dimensiones de un plano (...). El significado, el sentido, de las imágenes reside en sus propias superficies; puede captarse con una mirada (Flusser, 1990, p. 11).

Para explicar el conocimiento, muchas de las veces, se ha recurrido a la utilización de metáforas visuales, como representaciones en las que hay una ausencia de referente 0 se produce una ilusión referencial. No obstante, el sentido en que suelen utilizarse es acertado: no necesitan dicho objeto representado (Castañares, 2007). La capacidad humana de realizar inferencias se basa precisamente en la habilidad para elaborar y manipular estas estructuras simbólicas que pueden construirse indistintamente a partir de informaciones verbales o perceptivas. Escribe Johnson-Laird (1987) que los seres humanos comprenden el mundo construyendo en sus mentes modelos operativos de ese mismo mundo; debido a que no son completos, estos modelos son más simples que las entidades que representan. En consecuencia, los modelos contienen elementos que se reducen a puras y simples imitaciones de la realidad, elementos que no son modelos operativos del funcionamiento de sus correspondientes en el mundo real, sino solamente procedimientos que simulan su comportamiento.

Por tanto, el conocimiento es siempre "el resultado de una interpretación, la cual depende de toda la experiencia anterior del que interpreta y de su posición en el ámbito de una tradición" (Winograd y Flores, 1989, p.102). Toda interpretación es además un fenómeno contextual: no existe nada que se parezca a una comprensión objetiva y completa de un fenómeno, porque cada representación es ya una interpretación (Scolari, 2004). El mapa cognitivo, según Arnheim, parte de una construcción análoga o imaginativa, pero organiza la información categóricamente y por ello las imágenes son más bien una representación de un conjunto de reglas que permiten establecer inferencias (Tapia, 2004). Detrás de cada concepto se esconde una metáfora: en teoría cualquier cosa puede ser concebida en términos de otra. Toda metáfora implica: "La búsqueda de un modelo en otro lado, en otra serie, una conexión isomórfica que nos permita construir una explicación y ordenar el sentido frente a algo que nos resulta nuevo, inexplicable, o por lo menos no fácilmente formalizable" (Ford, 1994, p.43). Lakoff \& Johnson (1980) señalan que las metáforas son isomorfismos en cuanto que relacionan una estructura con otra estructura bajo el principio de la relevancia y de lo significativo. Los isomorfismos son pues la movilización de los lugares, y son por definición provisionales y no verdaderos o falsos sino localizados (Tapia, 2004).

Lakoff \& Johnson (1980) afirman que dependemos de nuestro conocimiento del espacio para conceptualizar el tiempo. Esta observación tiene mucho sentido, ya que tenemos detectores para el espacio (tacto, visión, oído, etc.) pero ninguno que detecte directamente el tiempo. El espacio, pues, resulta más básico que el tiempo en nuestra estructura conceptual porque es más palpable y menos abstracto. Mientras la mirada registradora se desplaza sobre la superficie de la imagen, va tomando de ésta un elemento tras otro: establece una relación temporal entre ellos. También es posible 
que regrese a un elemento ya visto y, así, transforme el antes en un después (Flusser, 1990). La dimensión temporal se construye mediante el registro y es, por tanto, una dimensión de regreso eterno. La mirada puede volver una y otra vez, sobre el mismo elemento de la imagen. Las dimensiones espaciales, como se reconstruyen mediante el registro, son aquellas relaciones llenas de significado, aquellos conjuntos en los que un elemento les da significado a todos los demás y, a cambio, recibe de ellos su propio significado. "La relación espacio-tiempo reconstruida a partir de la imagen es propia de la magia, donde todo se repite y donde todo participa de un contexto pleno de significado" (Ib., p. 12).

La representación en el plano bidimensional del espacio-tiempo toma como referentes conceptos y formas presentes en el mundo real, mediante elementos que son imitaciones de la realidad, aunque no constituyen modelos operativos del funcionamiento de sus correspondientes en el mundo real, sino solamente procedimientos que simulan su comportamiento, ya sea mediante analogías en un primer nivel, o mediante metáforas, en una construcción más elaborada.

En el diseño gráfico el espacio-tiempo para su representación utiliza analogías y metáforas espacio-temporales y tempo-espaciales, que permiten entender una realidad tangible y concreta en el plano de lo bidimensional. En este ejercicio de representar conceptos con diferente grado de concreción, como son el espacio y el tiempo, remite necesariamente a la utilización de analogías y metáforas, para establecer distintos grados de homologación con la realidad y para representar, en casos más difíciles, aquello que resulta imposible de manifestar literalmente, como el espacio-tiempo.

Los términos espaciales (direcciones: arriba, abajo; posiciones: vertical, horizontal, encima, debajo; centro; ejes: adelante y atrás; cerca, lejos; sobrepuesto, yuxtapuesto, fragmentado, etc.) y temporales (ser, estar, aquí, ahora; pasado, presente, futuro; recorrido: antes-durante-después; duración: corta, larga; avance, retroceso; suceso; instante, momento; secuencia, simultáneo; transcurrir; velocidad, movimiento, tiempo, dinámica, etc.) mediante la analogía y la metáfora ayudan a materializar en la representación el espacio-tiempo, a través de elementos morfológicos (punto, línea, plano, fondo-figura, textura, color, espacio, volumen, niveles de profundidad, traslapo, transparencia, deformaciones, tamaño, perspectiva, escala, oclusión, sombras, etc.), dinámicos (equilibrio, ritmo, simetría, armonía, contraste, etc.) y escalares (dimensión, proporción, escala, formato) que lo configuran y le otorgan significado, para homologar en mayor o menor grado lo perteneciente a la realidad concreta.

\section{Simplicidad y complejidad en la organización del espacio-tiempo}

En los años veinte se analizó la forma en términos de sus elementos geométricos básicos, creyendo que este sería un lenguaje fácilmente comprensible para todos, en tanto se apoyaba en un instrumento humano universal como es el ojo, y con ello, en la percepción. Los docentes de la Bauhaus acometieron esta idea desde diferentes 
puntos de vista, Kandinsky reclamó la creación de un diccionario de elementos y de una gramática visual universal; Moholy-Nagy trató de generar un vocabulario racional ratificado por una sociedad compartida y una humanidad común; Josef Albers señalaba la preeminencia del pensamiento sistemático sobre la intuición personal y pugnaba por la objetividad sobre la emoción (Lupton, 2009). Los diseñadores de la Bauhaus no solo creían en un modo universal de describir la forma visual, sino también en su significado universal. Al reaccionar contra esa creencia, la posmodernidad desacreditaba la experimentación formal como un componente primario del pensamiento y la realización de las artes visuales (Ib.).

En el campo del diseño, las bases de la Bauhaus y la Teoría Psicológica Gestalt han predominado; en ellas, el orden es el elemento principal que aglomera al conjunto de relaciones espaciales, formales, temporales, etc., el espacio y el tiempo son definidos, estáticos, puros, equilibrados; en cambio en el caos, el espacio-tiempo es fluido, ambiguo, viscoso o líquido, indecible e inclasificable; los límites se desmaterializan y transforman. Los espacios ya no tienen vértices, aristas, ángulos o lados, y el tiempo es una especie de vortex o vórtice (flujo turbulento en rotación espiral, puede considerarse cualquier tipo de flujo circular o rotatorio que posee movimiento).

A partir del estudio del orden y el caos, la simplicidad y la complejidad, se llega a comprender el conjunto, mediante el conocimiento de la posición específica que ocupa cada uno de éstos, las formas concretas que asumen, los conceptos, sus relaciones de interdependencia y contradicción con su opuesto, y de los elementos formales concretos que se emplean. La universalidad del espacio-tiempo reside también en su particularidad; por eso, al estudiar los conceptos precisos como el no-equilibrio, la inestabilidad, la asimetría, la no-linealidad, la discontinuidad, etc. se pueden establecer una serie de rasgos propios derivados de la universalidad contenida en el caos; en donde la identidad es la determinación de lo simple, inmediato y estático, mientras que la contradicción es la raíz de todo movimiento y vitalidad, el principio de todo automovimiento y solamente aquello que encierra una contradicción se transforma. Según una dialéctica de oposición de los extremos una cosa, una idea, una circunstancia histórica cualquiera, pueden ser tomadas como una posición, o sea como una tesis; como ninguna cosa, ni idea es completa y perfecta, frente a esa posición surge una que se le opone: la antítesis. De la confrontación o el encuentro entre estos dos opuestos surge la composición, la síntesis, que supera ambas posiciones anteriores y alcanza una nueva más completa, que las incluye a las dos; pero que está abierta a su vez a una nueva oposición, con lo que la evolución del concepto nunca se detiene. 


\section{CONTRADICCIONES EN EL ESPACIO-TIEMPO (ET)}

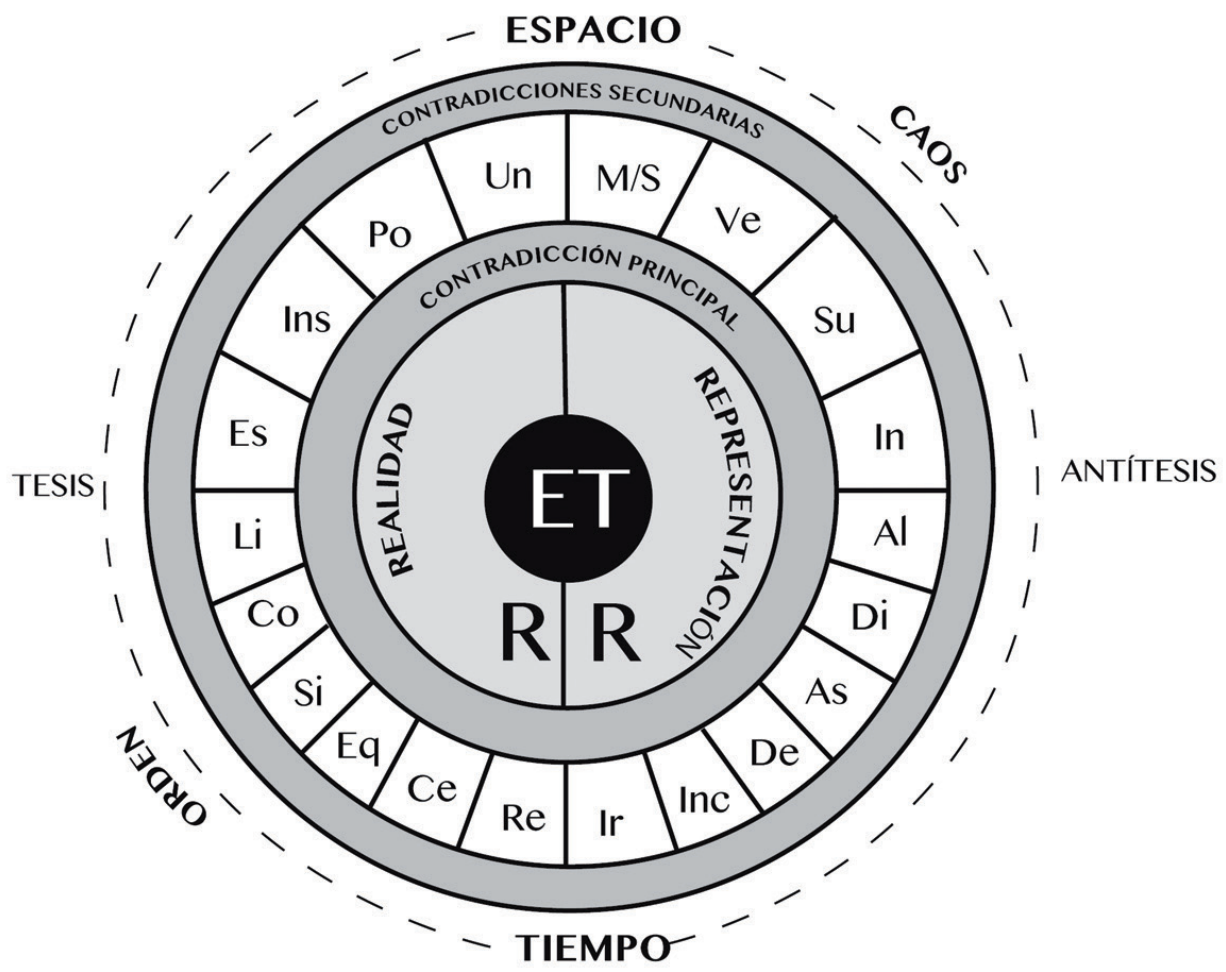

Figura 4. Esquema en el que se muestra la relación ESPACIO-TIEMPO (ET) a partir de la contradicción. Se observan conceptos contrapuestos, en principio por su naturaleza, en el plano de la realidad y de la representación. En donde Un (unicidad), M/S(multiplicidad, simultaneidad), Po (Posición), Ve (velocidad), Ins(instante), Su (suceso), Es (estabilidad), In (inestabilidad), Li (linealidad), Al (alinealidad), Co (continuidad, Di (discontinuidad), Si (simetría), As (asimetría), Eq (equilibrio), De (desequilibrio), Ce (certidumbre), Inc (incertidumbre), Re (realidad), Ir (irrealidad) (Mancilla, 2013).

En el diseño, la dialéctica diversidad-unidad es fundamental para la representación del espacio-tiempo en una composición. La diversidad está dada en los elementos configurantes, las relaciones de los mismos y sus estructuras (tendientes al desorden, al desequilibrio, a la asimetría, al contraste). Lo diverso no va en contra de lo unitario, muy al contrario, lo enriquece, creando un orden distinto a partir de elementos disímiles, a veces contradictorios, lo que da como resultado una propuesta visual más dinámica, mediante espacios-tiempos evidentes en la forma y las relaciones sintácticas (distintas, diversas, heterogéneas) de elementos. Berger también se refiere a esta dialéctica entre unidad y diversidad en la composición de la imagen afirmando 
que: "en la totalidad, cada uno de los elementos cede una parte de su unidad al conjunto y se transforma en virtud cualitativa" (1976, p.144).

La temporalidad, por su lado, se basa en la simultaneidad, en donde la estructura temporal depende del espacio, ya que está dada en los elementos espaciales y su sintaxis; sin embargo, cabe señalar que los elementos morfológicos no crean, con su mera presencia, esa estructura temporal progresiva, para ello necesitan ser activados, y esta función es precisamente la que cumplen los elementos dinámicos de la imagen como son la tensión y el ritmo. La clave, por tanto, para crear temporalidad en las imágenes está en la ordenación del espacio, en donde tiende a operar el caos como una alternativa para la representación de espacios-tiempos múltiples, yuxtapuestos y heterorreferenciados.

La simplicidad, en su relación de opuestos, se liga con la complejidad como respuesta al orden; ésta plantea una ruptura de principios de acción, en donde: la unidad, la cohesión, la unión, la armonía, el equilibrio, el punto muerto, el reposo, la permanencia, la uniformidad, el aglutinamiento, la atracción, etc., manifestaciones del estado de cambio cuantitativo de las cosas, cambian a la inversa; para la disolución del todo único, es decir, la destrucción de esa cohesión, unión, armonía, equilibrio, punto muerto, reposo, permanencia, uniformidad, aglutinamiento, atracción, y su transformación en sus respectivos contrarios, como manifestaciones del estado de cambio cualitativo de las cosas, es decir, de la transformación de un proceso en otro. Las conocimientos, las percepciones y las representaciones cambian de un estado a otro, lo que es importante para el caso del espacio-tiempo, en donde se echa mano de la complejidad para hacer más enfático el sentido que toma ahora el concepto en su resignificación (Tse-Tung, 1976). Entre la complejidad y la simplicidad, entre el orden y el caos, a pesar de ser elementos contrarios, se cuenta con la existencia de identidad y, por lo tanto, ambas pueden coexistir en un todo único y transformarse la una en la otra.

En los últimos años se ha tomado conciencia de estas teorías que reflejan la complejidad, en ellas, el caos se constituye como la puesta en crisis de los órdenes establecidos como verdades irrefutables, el caos es el cambio constante e impredecible en las fluctuaciones que hacen posible la evidencia del movimiento. El binomio del orden y el desorden suscita numerosas confrontaciones al igual que la simplicidad y la complejidad, el equilibrio y el desequilibrio, la simetría y la asimetría. El espacio-tiempo al contener dos elementos dialécticos ligados: un elemento creador del desorden y un elemento creador de orden, asocia normalmente el orden al equilibrio y el desorden a no-equilibrio; con el dominio de éste último, se establecen nuevas interacciones, que no por ello dejan de ser coherentes. Es un hecho nuevo, que contradice parte de lo que plantaba la Teoría de la Gestalt, en el paradigma clásico, en donde la totalidad, la buena forma, la simplicidad, etc., eran los principios fundamentales que la forma debía contemplar para el diseño. En una situación alejada del equilibrio, y de los fundamentos clásicos de la sintaxis visual, actualmente, se tiende a basar en las fluctuaciones, en lo no controlado, y ese cambio de paradigma, lleva a una situación nueva que da 
lugar a una serie de posibilidades variadas. El no-equilibrio tiene mayor relación con la cuestión espacial y temporal. En el espacio-tiempo como binomio, es más evidente ya que el equilibrio parece carecer de tiempo, de historia, es estático e inmóvil, y el no-equilibrio genera cambio, rompe el tiempo en fragmentos que son visibles en la representación. La probabilidad, inserta en el no-equilibrio, permite que se trasgreda la unicidad de la realidad física macroscópica que nos rodea, abre camino a la creatividad y con ello a la creación, a la concepción y materialización del binomio espacio-temporal y tempo-espacial.

La producción del espacio-tiempo va acompañada de la creación simultánea de orden y desorden, el desorden puede ser asociado a los elementos que parecen no estar en equilibrio y el orden a los elementos que logran establecer armonía. Son opuestos, pero su interacción favorece la generación de cambio y nuevos comportamientos se ligan también al no-equilibrio y a la no-linealidad, a la simetría y a la asimetría. Y es precisamente la ruptura de la simetría espacial la que genera la pérdida de la liga temporal entre pasado y futuro. La inestabilidad destruye el carácter de las trayectorias y modifica nuestros conceptos de espacio y tiempo (Prigogine, 2005). La noción de no-equilibrio y la ruptura de la simetría son elementos que determinan la concepción del tiempo.

\section{Conclusión}

El espacio y el tiempo, en el plano del diseño actual, son conceptos cuyo nexo se vuelve indisoluble, puesto que deben actuar como unidad, en donde algunas veces el espacio está contenido en el tiempo y, en otras, el tiempo se comprende en el espacio. Se liga al ser, al estar y al existir, y aún más allá, trasciende nuestras propias concepciones al sobrepasar el plano de la realidad material. En el espacio-tiempo, la representación se da mediante el uso de recursos visuales, los cuales constituyen una amplia gama de medios para la expresión visual del contenido, se presentan en forma de polos opuestos como aproximaciones contrarias y disímiles, lo que permite evidenciar en mayor medida este fenómeno.

La representación de este binomio se logra mediante la ruptura del espacio y del orden. A mayor caos visual, mayor representación del espacio-tiempo, lo que se posibilita mediante la aparición del tiempo a través de la fragmentación, presentándose características como: inestabilidad, irregularidad, asimetría, aleatoriedad, espontaneidad, actividad y variación; las cuales proveen a la obra del movimiento y con ello aparece representada la idea del tiempo. Complejidad, fragmentación, episodisidad, yuxtaposición, etc., son características que enfatizan la percepción de esos espacios y tiempos múltiples.

El espacio-tiempo en el campo de la representación bidimensional del diseño gráfico, por sí mismo, constituye una selección de la realidad, y se materializa en el diseño a través de un repertorio de elementos configurantes y estructuras específicas 
de representación; y el tiempo se asocia en mayor medida a la sintaxis, a la relación de dichos elementos, por tanto es de carácter perceptual y fenoménico. Entonces el espacio-tiempo se da en la medida en que el ojo lo capta y el cerebro lo interpreta mediante relaciones isomórficas (entre campo visual y el cerebral) que son las que permiten, a final de cuentas, establecer el nexo entre lo real y lo virtual. 


\section{Referencias bibliográficas}

Berger, R. (1976). El conocimiento de la pintura. El arte de verla. Barcelona: Noguer.

Beristáin, H. \& Beristáin, H. (2003). Diccionario de Retórica y Poética. México: Porrúa.

Castañares, W. (2007). Cultura Visual Y Crisis De La Experiencia. Cuadernos De Información Y Comunicación. Madrid: Universidad Complutense.

Ferrater, J. (2004). Diccionario de filosofía. Barcelona: Ariel S.A.

Flusser, V. (1990). Hacia una historia de la fotografía. México: Trillas.

Ford, A. (1994) Navegaciones. Buenos Aires: Amorrortu.

Johnson-Laird, P. (1987). Modelos mentales en ciencia cognitiva. En Norman, D. Perspectivas de la ciencia cognitiva. Cognición y desarrollo humano. Barcelona: Paidós.

Lakoff, G. \& Johnson, M. (1980). Metaphors We Live By, Chicago: University of Chicago Press.

Lupton, E. (2009). Diseño Gráfico Nuevos Fundamentos. Barcelona: Gustavo Gili.

Prigogine, I. (2005). El nacimiento del tiempo. Barcelona: Tusquets Editores.

Scolari, C. (2004). Hacer Clic: Hacia Una Sociosemiótica de las Interacciones Digitales. Barcelona: Gedisa. Tapia, A. (2004). Teoría y práctica: El diseño gráfico en el espacio social (1era ed.). México, D.F.: Designio. Tse-Tung, M. (1968). Sobre la Contradicción. Digitalizado y preparado para el internet: Por el Movimiento Popular Perú de Alemania, 1993. Recuperado de http://www.marxists.org

Winograd, T. \& Flores, F. (1989). Hacia la comprensión de la informática y la cognición. Barcelona: Editorial Hispano Europea.

Figuras

Figura 1. Magritte. (1929). La Trahison des images.

Figura 2. Mancilla, E. (2011). En el esquema se muestra la relación entre lo semejante, lo igual y lo idéntico en la analogía.

Figura 3. Mancilla, E. (2013). El gráfico ejemplifica las relaciones entre dos elementos que comparten una semejanza parcial, mediante semas comunes, gracias a los cuales se da la construcción de la metáfora.

Figura 4. Mancilla, E. (2013). Esquema en el que se muestra la relación ESPACIO-TIEMPO (ET) a partir de la contradicción. Se observan conceptos contrapuestos, en principio por su naturaleza, en el plano de la realidad y de la representación. En donde Un (unicidad), M/S(multiplicidad, simultaneidad), Po (Posición), Ve (velocidad), Ins(instante), Su (suceso), Es (estabilidad), In (inestabilidad), Li (linealidad), Al (alinealidad), Co (continuidad, Di (discontinuidad), Si (simetría), As (asimetría), Eq (equilibrio), De (desequilibrio), Ce (certidumbre), Inc (incertidumbre), Re (realidad), Ir (irrealidad). 